\title{
Erratum to: Small Vessel Disease and Memory Loss: What the Clinician Needs to Know to Preserve Patients' Brain Health
}

\author{
Christian Schenk • Timothy Wuerz • Alan J. Lerner
}

Published online: 2 March 2014

(C) Springer Science+Business Media New York 2014

Erratum to: Curr Cardiol Rep (2013) 15:427

DOI 10.1007/s11886-013-0427-6

On page 6, an error was made in the Conflict of Interest. The correct Conflict of Interest should be the following:

Christian Schenk and Timothy Wuerz declare that they have no conflict of interest.

Alan J. Lerner has been a consultant for Eli Lilly and Siemens; has given expert testimony for Easton and Smith, and Wulliger, Fadel, and Beyer; and has received royalties from Elsevier and Springer. He also has received grant support from Baxter Labs and Ceregene in association with ADCS; and has received travel/accommodations expenses covered or reimbursed from NIH-sponsored grant-related meetings.

The online version of the original article can be found at http://dx.doi.org/ 10.1007/s11886-013-0427-6.

C. Schenk $\cdot$ T. Wuerz $\cdot$ A. J. Lerner $(\bowtie)$

Department of Neurology, University Hospitals Case Medical

Center, 3619 Park East Drive, suite 211, Beachwood, OH 44122,

USA

e-mail: Alan.lerner@case.edu

\section{A. J. Lerner}

Case Western Reserve University School of Medicine, Cleveland,

$\mathrm{OH}$, USA 